KONSTAN
JURNAL FISIKA DAN PENDIDIKAN FISIKA
Volume 4, Nomor 1, Juni 2019
$\begin{array}{r}\text { E-ISSN : 2460-9129 dan P-ISSN : 2460-9110 } \\ \text { http://jurnalkonstan.ac.id/index.php/jurnal }\end{array}$

\title{
PENGEMBANGAN LKM BERBASIS MC-GP MENGGUNAKAN CAT UNTUK MELATIHKAN KEMAMPUAN BERPIKIR KRITIS MAHASISWA
}

\author{
Indro Wicaksono $^{1 *}$, Sutarto $^{2}$, Imam Marzuki $^{3}$ \\ 1)* Universitas Panca Marga, Probolinggo, Indonesia, \\ ${ }^{2)}$ Universitas Jember, Jember, Indonesia, \\ 3) Universitas Panca Marga, Probolinggo, Indonesia.
}

\section{Info Artikel}

Sejarah Artikel:

Diterima Desember 2018

Disetujui Juni 2019

Dipublikasikan Juni 2019

\section{Kata Kunci:}

Lembar Kerja Mahasiswa, Computer and Technology, Kinematika Gerak Lurus, Berfikir Kritis

\begin{abstract}
Abstrak
Tujuan penelitian ini adalah menghasilkan perangkat pembelajaran berupa Lembar Kegiatan Mahasiswa (LKM) berbasis Media Cetak Gambar Proses (MC-GP) menggunakan Computer And Thecnology (CAT) pada matakuliah Fisika Dasar materi kinematika gerak lurus yang layak digunakan untuk melatih kemampuan berpikir kritis mahasiswa. Subjek penelitian ini yaitu mahasiswa semester 1 prodi Teknik Industri dan Teknik Elektro Universitas Panca Marga (UPM) Tahun Ajaran 2018/2019. Kemampuan berpikir kritis yang diukur menyesuaikan dengan indikator berpikir kritis yang disingkat dengan FRISCO. Model pengembangan yang digunakan merujuk pada model pengembangan 4-D dengan tahapan Definition, Design, Development, dan Dissemination. Desain penelitian yang digunakan yaitu One group pretest-postest design. Teknik pengumpulan data penelitian menggunakan instrumen penelitian yang meliputi instrumen validasi LKM dari ahli media, instrumen tes kemampuan berpikir kritis (TKBK) berupa tes, dan instrumen respon mahasiswa berupa angket. Hasil penelitian yang dihasilkan menunjukkan bahwa hasil validasi LKM MC-GP dan TKBK berkategori valid. Hasil TKBK mahasiswa mengalami peningkatan dengan skor ratarata peningkatannya 0,73 (gain tinggi). Respon mahasiswa terhadap penggunakan LKM MC-GP berkategori sangat setuju.
\end{abstract}

(C) 2019 Universitas Islam Negeri Mataram

\footnotetext{
* Corresponding Author: indro.upm@gmail.com

Alamat korespodensi:

Gedung Pasca Sarjana Lantai 3 Kampus 2 UIN Mataram, Jl. Gajah Mada 100 Jempong Mataram, Indonesia

Email: jurnalkonstan@uinmataram.ac.id
} 


\section{PENDAHULUAN}

Peraturan Presiden No 8 Tahun 2012 tentang Kerangka Kualifikasi Nasional Indonesia (KKNI) menyebutkan bahwa lulusan sarjana memiliki 3 kompetensi diantaranya adalah 1) menerapkan IPTEKS berdasarkan bidangnya, 2) menguasai konsep teoritis bidang pengetahuan secara mendalam, dan 3) mengambil keputusan yang tepat berdasarkan analisis informasi dan data dengan penuh tanggung jawab [1]. Berdasarkan uraian tersebut, sangatlah jelas bahwa untuk memenuhi ketiga kompetensi tersebut, mahasiswa lulusan srata-1 harus memiliki high order thinking skill (kemampuan berpikir tingkat tinggi). Salah satu kategori kompetensi yang merupakan kategori HOTS adalah kemampuan berpikir kritis (critical thingking). Kemampuan berpikir kritis adalah cara berpikir reflektif dan masuk akal atau berdasarkan nalar yang difokuskan untuk menentukan apa yang harus diyakini dan dilakukan [2].

Penjelasan di atas menunjukkan bahwa perlunya perangkat pembelajaran yang dapat membelajarkan mahasiswa dalam perkuliahan yang terintegrasi dengan kemampuan berpikir kritis. Langkah yang tepat untuk melatihkan kemampuan berpikir kritis tersebut adalah dengan mengembangkan lembar kegiatan mahasiswa (LKM). Dengan menggunakan LKM ini mahasiswa dapat mengkonstruksi pengetahuannya secara mandiri melalui kegiatan yang terdapat di dalam LKM. Untuk melatihkan kemampuan berpikir kritis pada perkuliahan, maka kegiatan di dalam LKM diintegrasikan dengan indikator berpikir kritis. Indikator berpikir kritis yang digunakan mengadopsi dari Ennis (2011) dengan indikator yang meliputi Focus, Reason, Interference, Situation, Clarity, dan Overview (FRISCO).

Penyajian indikator kemampuan berpikir kritis di atas, diintegrasikan dengan metode Gambar Proses (GP). Sutarto, dkk (2018) menyebutkan bahwa definisi GP adalah rangkaian gambar objek (benda, kejadian, atau fenomena yang bersifat riil maupun abstrak, yang dapat dilihat maupun hanya dapat dibayangkan) yang gambar-gambar dalam rangkaian tersebut antara gambar satu dengan lainnya selalu terlihat ada relative perbedaan dalam hal (keadaan, kedudukan, bentuk, maupun kombinasinya) yang secara keseluruhan menggambarkan suatu tahapan yang runtut dan kesatuan yang utuh [3]. Berdasarkan definisi tersebut, maka diperlukan bantuan computer and technology (CAT) agar GP yang dicetak memiliki tampilan yang menarik dan sequencing (terurut). Sehingga, hasil GP dari CAT yang dicetak digunakan sebagai media pembelajaran yang disebut sebagai Media Catak Gambar Proses (MC-GP).

Hasil penelitian yang pernah dilakukan oleh Wicaksono (2016) tentang profil kemampuan eksperimen mahasiswa berbasis inkuiri terbimbing pada percobaan Hukum Ohm telah menunjukkan bahwa kemampuan mahasiswa Teknik elektro UPM semester 1 dalam melaksanakan ekperimen berkategori kurang baik [4]. Hal ini dikarenakan bahwa kemampuan berpikir ilmiah mahasiswa masih kurang. Salah satu upaya untuk meningkatkan kemampuan berpikir ilmiah mahasiswa yaitu dengan melatihkan kemampuan berpikir kritis. Untuk melihat adanya peningkatan kemampuan berpikir kritis mahasiswa, maka perlu diintegrasikan dalam pelaksanaan perkuliahan dengan cara mengubah pembelajaran mahasiswa menjadi berpusat pada mahasiswa menggunakan bantuan LKM. LKM yang 
dikembangkan dalam penelitian ini menggunakan MC-GP dengan bantuan CAT. Berdasarkan uraian tersebut, tujuan dari penelitian ini adalah yang pertama mendeskripsikan validitas LKM berbasis MC-GP menggunakan CAT yang telah dikembangkan diintegrasikan dengan indikator berpikir kritis. Kedua bertujuan untuk mendeskripsikan kemampuan berpikir kritis mahasiswa setelah pelaksanaan pembelajaran menggunakan LKM berbasis MC-GP menggunakan CAT yang telah dikembangkan. Ketiga bertujuan untuk mendeskripsikan respon mahasiswa setelah pelaksanaan pembelajaran menggunakan LKM berbasis MC-GP menggunakan CAT yang telah dikembangkan.

\section{METODE PENELITIAN}

Desain penelitian yang digunakan dalam penelitian ini adalah One group pretest-postest design. Subjek penelitian ini adalah mahasiswa program studi Teknik Industri semester 1 UPM Probolinggo berjumlah 9 mahasiswa dan mahasiswa Teknik Elektro semester 1 UPM Probolinggo berjumlah 10 mahasiswa. Pemilihan mahasiswa ini berdasarkan adanya matakuliah semester 1 yaitu Fisika Dasar I materi Kinematika Gerak Lurus. Objek penelitian ini yaitu kemampuan berpikir kritis. Metode dalam penelitian ini menggunakan metode penelitian deskriptif kuantitatif dan kualitatif. Data yang diperoleh dari penelitian ini yaitu hasil validasi LKM dari ahli media, lembar observasi pelaksanaan pembelajaran, respon mahasiswa, dan Tes Kemampuan Berpikir Kritis (TKBK). Model pengembangan LKM yang dikembangkan oleh peneliti mengadopsi pada model pengembangan 4-D Thiagarajan dan Semmel (1974) yang meliputi tahap pendefinisian (Define), tahap perancangan (Design), tahap pengembangan (Development), dan tahap penyebaran (Disseminate) [5].

Instrumen penelitian yang digunakan dalam penelitian ini meliputi instrumen validitas LKM MC-GP yang diintegrasikan dengan indikator berpikir kritis dan TKBK. Penilaian validitas tersebut diperoleh dari para ahli media dan materi serta TKBK dengan mengadaptasi kriteria skor rata-rata validitas dari Ratumanan \& Laurens (2011) sebagai berikut ini [6].

Tabel 1. Kriteria skor rata-rata

\begin{tabular}{|c|c|c|}
\hline No & Interval Nilai & Kriteria \\
\hline 1 & $\bar{x}>3,6$ & Sangat baik \\
\hline 2 & $2,8 \leq \bar{x} \leq 3,6$ & Baik \\
\hline 3 & $1,9 \leq \bar{x} \leq 2,7$ & Tidak baik \\
\hline 4 & $1,0 \leq \bar{x} \leq 1,8$ & Sangat tidak baik \\
\hline
\end{tabular}

Sedangkan tingkat reliabilitas dihitung dengan rumus menurut Borich (1994) [7]:

$$
R=\left(1-\frac{A-B}{A+B}\right) \times 100 \%
$$


Sedangkan hasil angket respon mahasiswa dihitung berdasarkan rumus yang dikembangkan oleh Riduwan (2010) sebagai berikut ini [8]:

$$
\% \text { Kriteria }=\frac{\text { jumlah skor total }}{\text { skor kriteria }} \times 100 \%
$$

dengan kriteria skala Likert respon mahasiswa sebagai berikut.

Tabel 2. Persentase Skor respon mahasiswa

\begin{tabular}{|c|c|c|}
\hline No & Persentase Skor & Kriteria Persepsi \\
\hline 1 & $0 \%-20 \%$ & Sangat lemah \\
\hline 2 & $21 \%-40 \%$ & Lemah \\
\hline 3 & $41 \%-60 \%$ & Cukup \\
\hline 4 & $61 \%-80 \%$ & Kuat \\
\hline 5 & $81 \%-100 \%$ & Sangat Kuat \\
\hline
\end{tabular}

\section{HASIL DAN PEMBAHASAN}

\section{A. Hasil Penelitian}

Data hasil validitas LKM MC-GP yang telah dikembangkan berdasarkan indikator berpikir kritis dan TKBK dari dua ahli media dan materi ditunjukkan dengan data grafik dibawah ini.

Grafik Mean Skor Penilaian berdasarkan Aspek Penilaian LKM

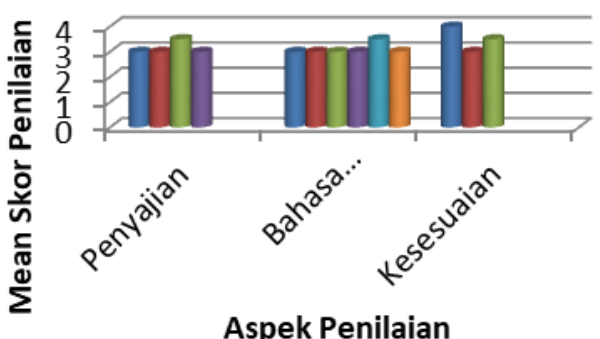

(a)
Grafik Mean Skor Penilaian berdasarkan Aspek Penilaian TKBK

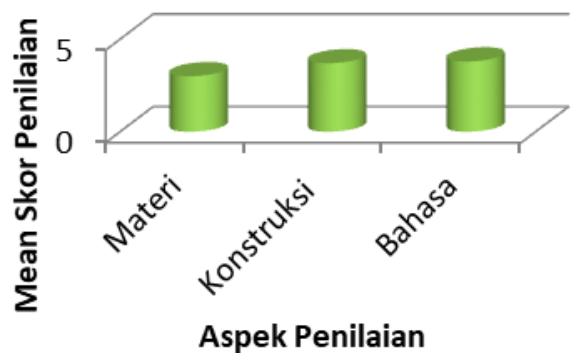

(b)

Gambar 1. Mean Skor Perolehan Validasi

Berdasarkan grafik mean skor penilaian di atas pada Gambar 1(a) aspek penilaian penyajian pada diagram batang di atas dihasilkan mean skor penilaian sebesar 3.1, pada aspek bahasa dan keterbacaan dihasilkan mean skor penilaian sebesar 3.1, sedangkan pada aspek kesesuaian untuk mean penilaian diperoleh sebesar 3.5. Sehingga, mean skor untuk penialian LKM MC-GP sebesar 3.2 dengan kategori baik dan reliabilitas sebesar 94\% dengan kategori reliabel. Sedangkan, pada Gambar 1(b) pada aspek materi dihasilkan mean skor penilaiannya sebesar 
3.0, pada aspek konstruksi dihasilkan mean skor penilaian sebesar 3.7, dan pada aspek bahasa dihasilkan mean skor penilaian sebesar 3.8. Sehingga, mean skor penilaian secara keseluruhan adalah sebesar 3.5 dengan kategori baik dan reliabilitas sebesar $88 \%$ dengan kategori reliabel. Berdasarkan uraian tersebut, dapat disimpulkan bahwa LKM MC-GP dan TKBK yang dihasilkan valid.

\section{B. Pembahasan}

Setelah LKM MC-GP dan TKBK dinyatakan valid, maka peneliti melakukan ujicoba LKM MC-GP dan TKBK dalam perkuliahan fisika dasar baik dari mahasiswa Teknik Elektro UPM 10 mahasiswa dan Teknik Industri 9 mahasiswa. Pelaksanaan LKM MC-GP dilakukan pada materi kinematika gerak lurus yang diintegrasikan dengan indikator berpikir kritis yang meliputi tahapan Focus (pada tahapan ini disajikan gambar proses secara lengkap dengan tujuan mahasiswa dapat menyebutkan besaran-besaran fisika yang disajikan), Reason (pada tahapan ini mahasiswa diharapkan mampu menyebutkan variabel besaran yang diperlukan dan membuat rumusan masalah yang tepat berdasarkan gambar proses yang disajikan), Interference (pada tahapan ini mahasiswa dapat membuat hipotesis dari rumusan masalah yang telah dibuat), Situation (pada tahapan ini mahasiswa dapat melengkapi isian data baik berupa tabel maupun grafik), Clarity (pada tahapan ini mahasiswa dapat menjelaskan kembali hubungan antar variabel atau hasil isian grafik ataupun tabel yang telah dilengkapiserta membuat kesimpulan), Overview (pada tahapan ini mahasiswa dapat menyelesaian permasalahan yang berkaitan dengan fenomena nyata yang disajikan).

Untuk melihat dampak yang diberikan kepada responden dengan total jumlah respoden sebesar 19 mahasiswa, maka perlu dilakukan pretest sebelum dilaksanakan perkuliahan menggunakan LKM MC-GP. Setelah itu, dilaksanakan penggunaan LKM MC-GP pada materi kinematika gerak lurus yang dibagi menjadi 3 pertemuan dengan hasil pertemuannya sebagai berikut.

(a) Pertemuan 1

Pada pembelajaran awal topik yang disajikan yaitu Gerak Lurus Beraturan (GLB). Pada bagian ini respon dari responden ketika mengamati gambar proses yang disajikan teramati sangat antusias, dengan menganalisis gambar. Pada bagian ini, 12 responden dari 19 responden mengalami kesulitan dibagian tahapan interference (membuat hipotesis), situation (melengkapi data dalam bentuk tabel dan grafik), dan clarity (membuat penjelasan hubungan antarbesaran fisika dan kesimpulan).

\section{(b) Pertemuan 2}

Pada pertemuan ini topik yang dipelajari yaitu Gerak Lurus Berubah Beraturan (GLBB). Pada bagian ini, 15 responden dari 19 responden yang dilaksanakan ujicoba LKM MC-GP membutuhkan waktu cukup lama dalam mengamati gambar proses yang disajikan (focus). Tetapi, untuk 
setiap langkah berpikir kritis dapat diselesaikan dengan baik. responden juga teramati cukup membutuhkan waktu untuk menyelesaikan tahapan overview.

\section{(c) Pertemuan 3}

Pada pertemuan ini topik yang dipelajari yaitu gerak vertikal. Pada tahapan ini, responden kesulitan dengan arah gambar percepatan gravitasinya. 5 responden dari 9 responden mengalami kesulitan pada tahap clarity (memformulasikan persamaan yang diperlukan).

Berdasarkan hasil penelitian di atas, pada tahap berikutnya dilakukan posttest kepada 19 responden. Setelah itu, membandingkan hasil pretest dan posttest setiap responden dengan analisis $\mathrm{N}$-gain yang dikembangkan oleh Kahe (1999) sebagai berikut.

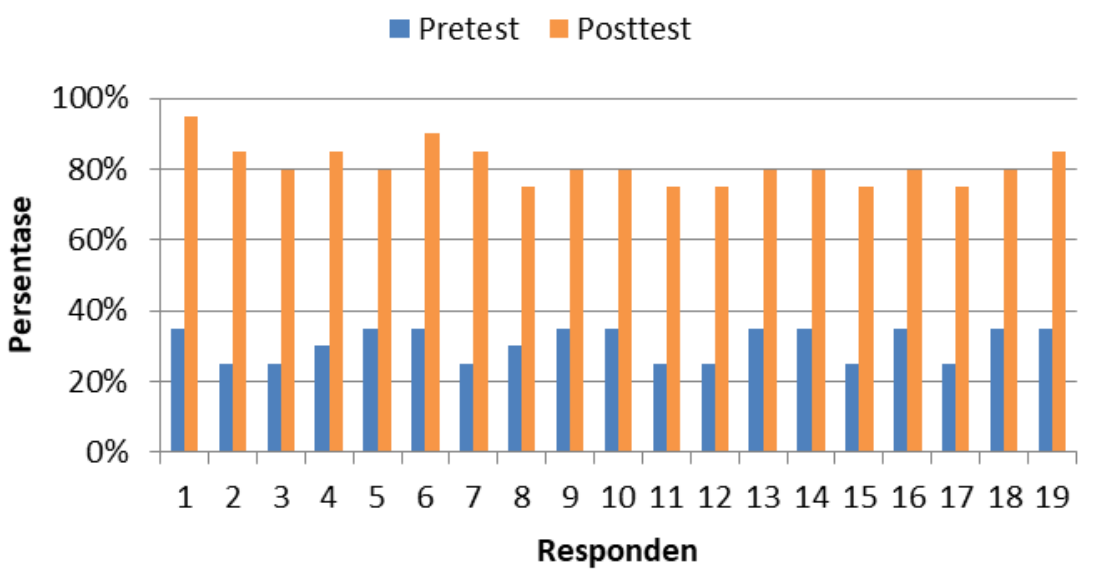

Gambar 2. Hasil TKBK pada pretest dan posttest

Hasil grafik di atas menunjukkan bahwa adanya peningkatan yang nyata pada kemampuan berpikir kritis dari 19 responden yang tampak bahwa adanya peningkatan nilai dalam persentase 0\% - 100\%. Berdasarkan analisis N-gain diperoleh nilai rata-rata $\mathrm{N}$-gain dari 19 responden sebesar 0,73 dengan kategori gtinggi. Sehingga, dapat disimpulkan bahwa LKM MC-GP yang dikembangkan dapat meningkatkan kemampuan berpikir kritis mahasiswa dan layak untuk melatihkan kemampuan berpikir kritis mahasiswa.

\section{SIMPULAN DAN SARAN}

Berdasarkan uraian di atas, dapat disimpulkan bahwa pengembangan LKM berbasis MC-GP menggunakan CAT layak digunakan untuk melatihkan kemampuan berpikir kritis mahasiswa. Saran peneliti untuk penelitian berikutnya, 
agar dampak perlakuan penggunaan LKM berbasis MC-GP lebih signifikan perlu adanya kelompok eksperimen dan kelompok kontrol.

\section{DAFTAR PUSTAKA}

[1] Wicaksono, I. (2016). Profil Kemampuan Eksperimen Mahasiswa Berbasis Inkuiri Terbimbing pada Percobaan Hukum Ohm. ENERGY, 6 (2), 21-26.

[2] Sutarto, dkk. (2018). Gambar Proses. Jember: Universitas Jember.

[3] Anonim.Perpres No. 08 Tahun 2012.

[4] Ennis, R. (2011). The Nature of Critical Thingking: An Outline of Critical Thingking Dispositions and Abilities. University of Illinois.

[5] Thiagarajan, S. Semmel, D.S \& Semmel, MI. (1974). Instruction Developmnet for training Teachers of Exceptional Children. Indiana: Indiana University Bloomington..

[6] Ratumanan, G.T \& Laurens, T. (2011). Evaluasi Hasil Belajar pada Tingkat Satuan Pendidikan. Surabaya: UNESA Univerity Press.

[7] Borich, D.D. (1994). Obsevation Skill of Effective Teaching. New York: Macmillian Publishing Company.

[8] Riduwan. (2010). Belajar Mudah Penelitian. Bandung: Alfabeta. 